\title{
Better pain control with 8-gray single fraction palliative radiotherapy for skeletal metastases: a Bayesian network meta-analysis
}

\author{
Filippo Migliorini $^{1}$ (D) Jörg Eschweiler ${ }^{1} \cdot$ Andromahi Trivellas $^{2} \cdot$ Arne Driessen $^{1} \cdot$ Matthias Knobe $^{3} \cdot$ Markus Tingart $^{1}$. \\ Nicola Maffulli ${ }^{4,5,6}$
}

Received: 13 October 2020 / Accepted: 20 November 2020 / Published online: 9 February 2021

(c) The Author(s) 2021

\begin{abstract}
External Beam Radiotherapy (EBRT) allows remarkable pain control in patients with skeletal metastases. We performed a Bayesian network meta-analysis comparing the most commonly used radiotherapy regimens for palliative management in patients with skeletal metastases. The main online databases were accessed in October 2020. All randomized clinical trials evaluating the irradiation of painful bone metastases were considered. The following irradiation patterns were analysed and included in the present network meta-analysis: $8 \mathrm{~Gy}$ - and $10 \mathrm{~Gy} /$ single fraction, $20 \mathrm{~Gy} / 5$ fractions, $30 \mathrm{~Gy} / 10 \mathrm{fractions}$. The Bayesian hierarchical random-effect model analysis was adopted in all comparisons. The Log Odds-Ratio (LOR) statistical method for dichotomic data was adopted for analysis. Data from 3595 patients were analysed. The mean follow-up was 9.5 ( 1 to 28 ) months. The cumulative mean age was $63.3 \pm 2.9 .40 .61 \%$ (1461 of 3595 patients) were female. The $8 \mathrm{~Gy} /$ single fraction protocol detected reduced rate of "no pain response" (LOR 3.39), greater rate of "pain response" (LOR-5.88) and complete pain remission (LOR-7.05) compared to the other dose patterns. The 8Gy group detected a lower rate of pathological fractures (LOR 1.16), spinal cord compression (LOR 1.31) and re-irradiation (LOR 2.97) compared to the other dose patterns. Palliative $8 \mathrm{~Gy} /$ single fraction radiotherapy for skeletal metastases shows outstanding results in terms of pain control, re-irradiations, pathological fractures and spinal cord compression, with no differences in terms of survivorship compared to the other multiple dose patterns.
\end{abstract}

Level of evidence: I, Bayesian network meta-analysis of RCTs.

Keywords Radiotherapy $\cdot$ Bone metastases $\cdot$ Pain $\cdot$ Fracture $\cdot$ Survivorship

Filippo Migliorini

migliorini.md@gmail.com

1 Department of Orthopaedic Surgery, RWTH University Hospital Aachen, Pauwelsstraße 30, 52074 Aachen, Germany

2 Department of Orthopaedics, David Geffen School of Medicine at UCLA, Suite 755, Los Angeles, CA 90095, USA

3 Department of Orthopedics and Trauma Surgery, Lucerne Cantonal Hospital, Lucerne 6000, Switzerland

4 Department of Medicine, Surgery and Dentistry, University of Salerno, Via S. Allende, 84081 Baronissi, SA, Italy

5 School of Pharmacy and Bioengineering, Keele University School of Medicine, Thornburrow Drive, Stoke on Trent, England

6 Barts and the London School of Medicine and Dentistry, Centre for Sports and Exercise Medicine, Queen Mary University of London, Mile End Hospital, 275 Bancroft Road, London E1 4DG, England

\section{Introduction}

Metastatic disease is a common source of bone pain [1]. Bone metastases are debilitating and lead to pain, impaired mobility, malignant hypercalcemia, pathological fractures, and, when the spinal cord is involved, neurological disability [2]. Also, severe hypercalcemia can lead to cardiac and kidney failure [3], with marked decrease in median survival [4]. As lung, thyroid, and renal cancer, multiple myeloma and melanoma often metastasize to bone [5, 6], bone metastases are common in the spine, pelvis and hip, shoulder, and distal femur [7] with elbow and knee metastases typical of lung cancer metastases [8]. The exact incidence of bone metastases is still unknown [3], but they impact greatly on patients and health care systems [9]. Approximately $70 \%$ to $90 \%$ of the patients who died from breast or prostate cancer develop bone metastases [10,11]. Over the past several years, an increased interest on External beam radiotherapy 
(EBRT) as management for selected patients with skeletal metastases has emerged [12]. EBRT achieved satisfactory results in pain control along with reduced burden in terms of both hospital attendances and side effects [13-15]. The dose pattern is measured in Gray (Gy), while the number of sessions is called fractions. Several studies have shown that $30 \mathrm{~Gy}$ in 10 fractions, $20 \mathrm{~Gy}$ in 5 fractions, or $8 \mathrm{~Gy}$ in a single fraction afford optimal pain control with acceptable adverse effects [16]. Given the complexity and lack of consensus concerning the palliative radiotherapy for patients with skeletal metastases, we performed a Bayesian network meta-analysis comparing the three most commonly used dose patterns: $8 \mathrm{~Gy}$ in one fraction, 20Gy and 30Gy in five and ten fractions, respectively.

\section{Material and methods}

\section{Search strategy}

The present Bayesian network meta-analysis was performed according to the PRISMA extension statement for reporting of systematic reviews incorporating network meta-analysis of health care interventions [17]. To guide the search, a preliminary protocol was performed:

- P (population): skeletal metastases;

- I (intervention): palliative radiotherapy;

- C (comparison): 8Gy vs 20Gy vs 30Gy;

- $\mathrm{O}$ (outcomes): pain scores and medications, further therapies, side effects, survivorship.

\section{Literature search}

Two authors (FM; JE) independently performed the literature search in October 2020. The databases accessed were Pubmed, Google Scholar, Scopus. The following keywords were used alone and in combination: metastasis, skeletal, bone, radiotherapy, irradiation, Gray, survivorship, pain, treatment, fractures, spinal cord compression, cancer, 8Gy, 20Gy, 30Gy. The same authors independently screened the resulting articles. If title and subsequent abstract matched the topic, the full-text article was accessed. The bibliographies of the studies of interest were also reviewed by hand.

\section{Eligibility criteria}

All randomized clinical trials evaluating irradiation of painful bone metastases were considered for analysis. Only articles of level I evidence according to the Oxford Centre of Evidenced-Based Medicine [18] were included in the present study. Given the authors languages capabilities, articles in English, German, Italian, Portuguese and Spanish were considered eligible. Letters to editors, expert opinions, case series, and other review articles were not considered for analysis. Cadaveric, animal, in vitro or computational study were excluded. The following irradiation patterns were analysed and included in the present network meta-analysis: $8 \mathrm{~Gy}$ and 10Gy in one fraction, 20Gy in five fractions, 30GY in 10 fractions. Articles reporting data concerning different irradiation patterns were excluded. Only articles providing quantitative data under the outcomes of interest were included. Missing data under the outcomes of interest warranted the exclusion from the present work. Disagreements between the authors were mutually debated and solved.

\section{Outcomes of interest}

Two authors (FM; JE) independently extracted data from the included articles. The following variables were collected: author and year of publication, follow-up duration, number of treated patients and respective mean age and gender. Furthermore, the inclusion and exclusion criteria were reported along with the site of the primary tumour and localization of metastases. Concerning the treatment, we collected data regarding irradiation site and doses, pre- and post-treatment pain scores and medication, further therapies, side effects and survivorship.

\section{Statistical analysis}

The statistical analysis was performed by the main author (FM). To analyse patient baseline comparability, the analysis of variance (ANOVA) test was performed, with values of $P$ $>0.1$ considered satisfactory. The endpoint pain medication consumption relates to the percentage of patients using that drug. For analytical statistics, the STATA Software/MP (STATACorp, College Station, TX) was used. The Bayesian hierarchical random-effect model analysis was adopted in all comparisons. A reference value was set in all comparisons. The Log Odds-Ratio (LOR) and standard error (SE) statistical method for dichotomic data was adopted for analysis. The edge plot was performed to evaluate contribution of direct and indirect comparisons among the networks. To verify transitivity among studies, the overall inconsistency was evaluated through the equation for global linearity via the Wald test. Values of $\mathrm{P}>0.05$ could not reject the null hypothesis, and the consistency assumption could be accepted at the overall level of each treatment. The overall estimated effect of the comparisons and ranking for each endpoint was evaluated through the interval plot. Both the confidence interval (CI) and percentile interval (PrI) was set 
at $95 \%$. Funnel plots were performed to evaluate the risk of publication bias among the studies.

\section{Results}

\section{Literature search}

The literature search resulted in 188 publications, of which 41 were duplicates. A further 82 articles were excluded because not matching the eligibility criteria: not randomized trial or poor level of evidence (45); concerning different doses or fractionations and radiotherapeutic protocols (23); language limitation (1), uncertain results (3), other (10). Another 45 articles were rejected for not reporting quantitative data under the outcomes of interest. Finally, 15 randomized clinical trials were eligible for analysis in the present study (Fig. 1).

\section{Study demographics}

In the present Bayesian network meta-analysis, data from 3595 patients were analysed. The mean follow-up was 9.5 (1 to 28 ) months. The cumulative mean age was $63.3 \pm 2.9$.
$40.61 \%$ (1461 of 3595 patients) were female. The ANOVA test evidenced no differences regarding age or sex of patients among the studies at baseline $(\mathrm{P}>0.5)$. Demographic data are shown in Table 1.

\section{Pain medication consumption and survivorship}

Pain medication consumption was not analysed in the 20Gy group because of lack of quantitative data. Administration of pain medication was notably reduced post-treatment in the $8 \mathrm{~Gy}$ and $30 \mathrm{~Gy}$ groups. No administration of pain medication improved to $+19.50 \%$ and $+21.83 \%$ in the $8 \mathrm{~Gy}$ and $30 \mathrm{~Gy}$ groups, respectively, while the use of nonsteroidal anti-inflammatory drugs (NSAID) was reduced to $-13.92 \%$ and $-8.65 \%$. Overall consumption of weak narcotics was reduced to $-3.33 \%$ and $-8.50 \%$ in the $8 \mathrm{~Gy}$ and 30Gy groups, respectively. The intake of strong narcotics was reduced to $-18.25 \%$ in the $8 \mathrm{~Gy}$ group, while in the $30 \mathrm{~Gy}$ group an increase to $+3.80 \%$ was detected during last follow-up. The mean survival was $7.93 \pm 1.87$ months in the $8 \mathrm{~Gy}$ group, $6.65 \pm 2.62$ months in the $20 \mathrm{~Gy}$ group, and 8.71 \pm 0.8 months in the $30 \mathrm{~Gy}$ treatment group. Pain medication consumption and survivorship are shown in Table 2.

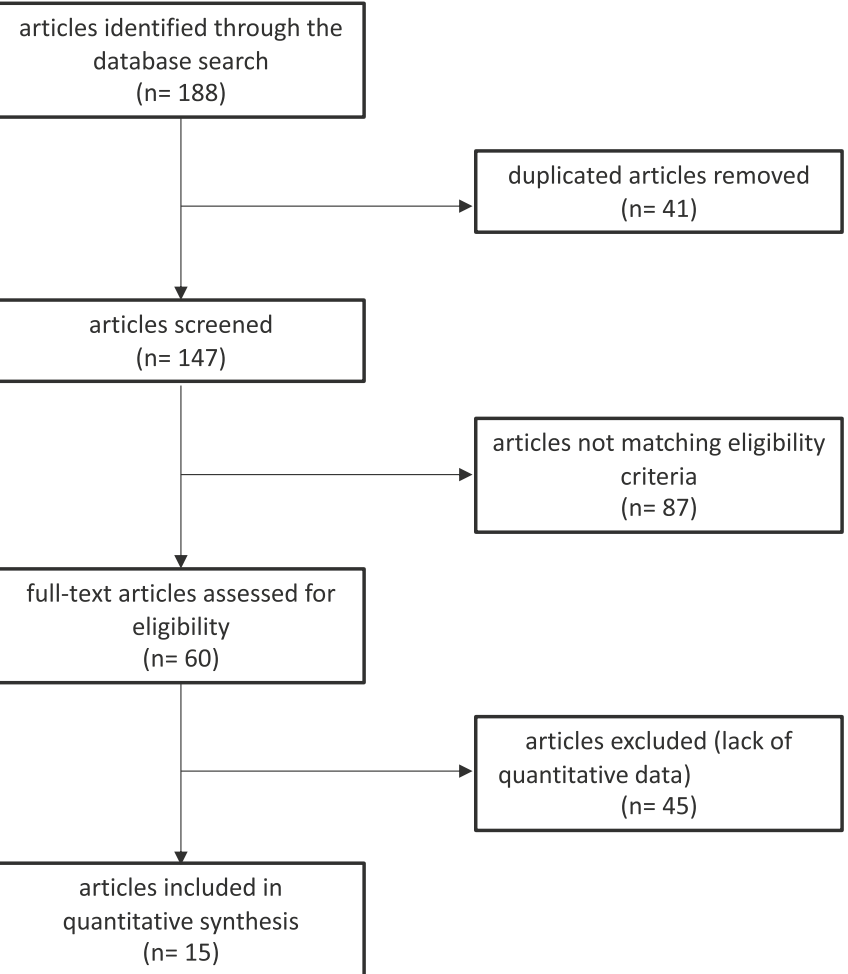

Fig. 1 Flow-chart of the literature search

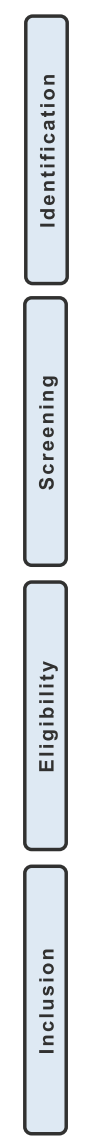




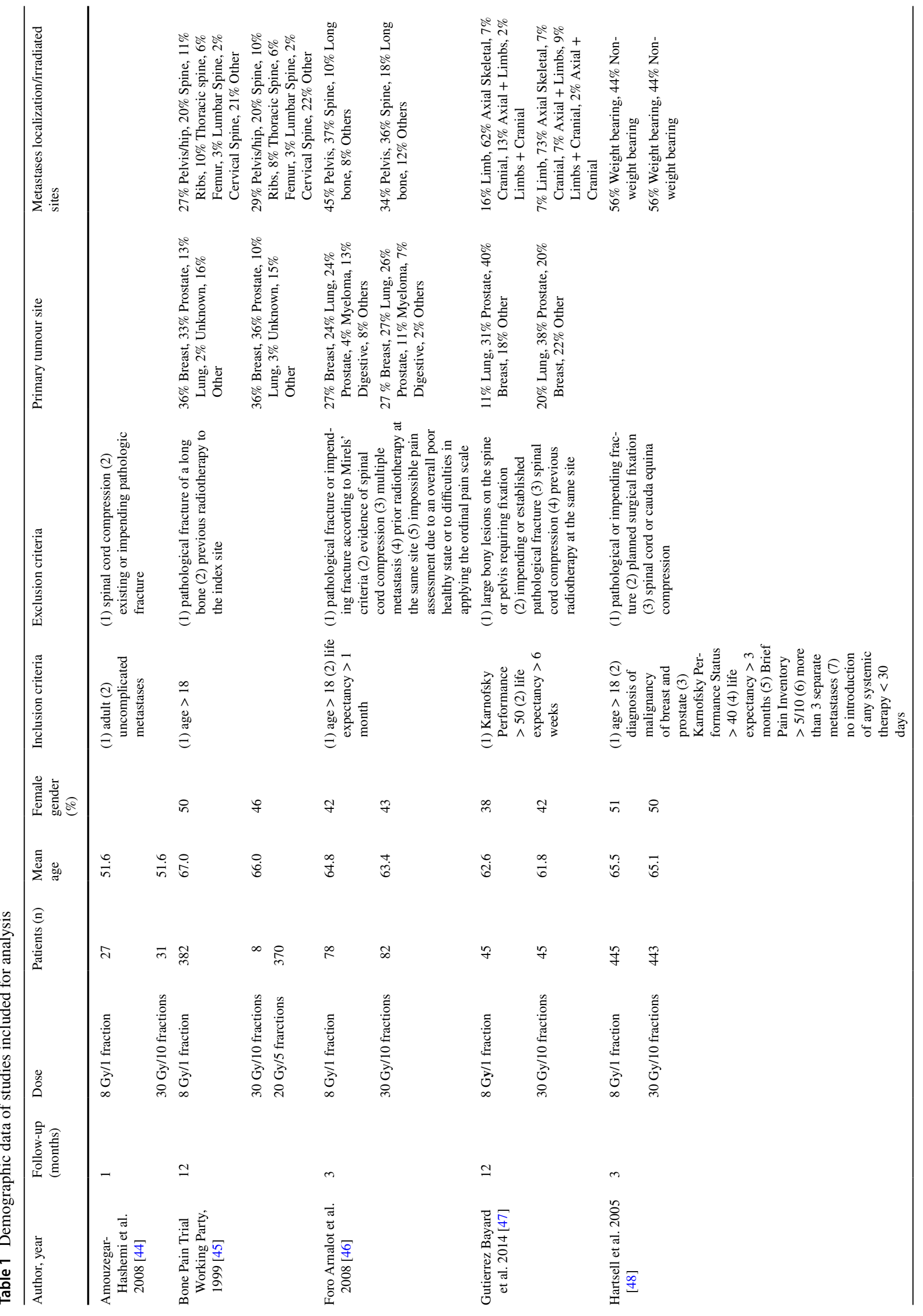




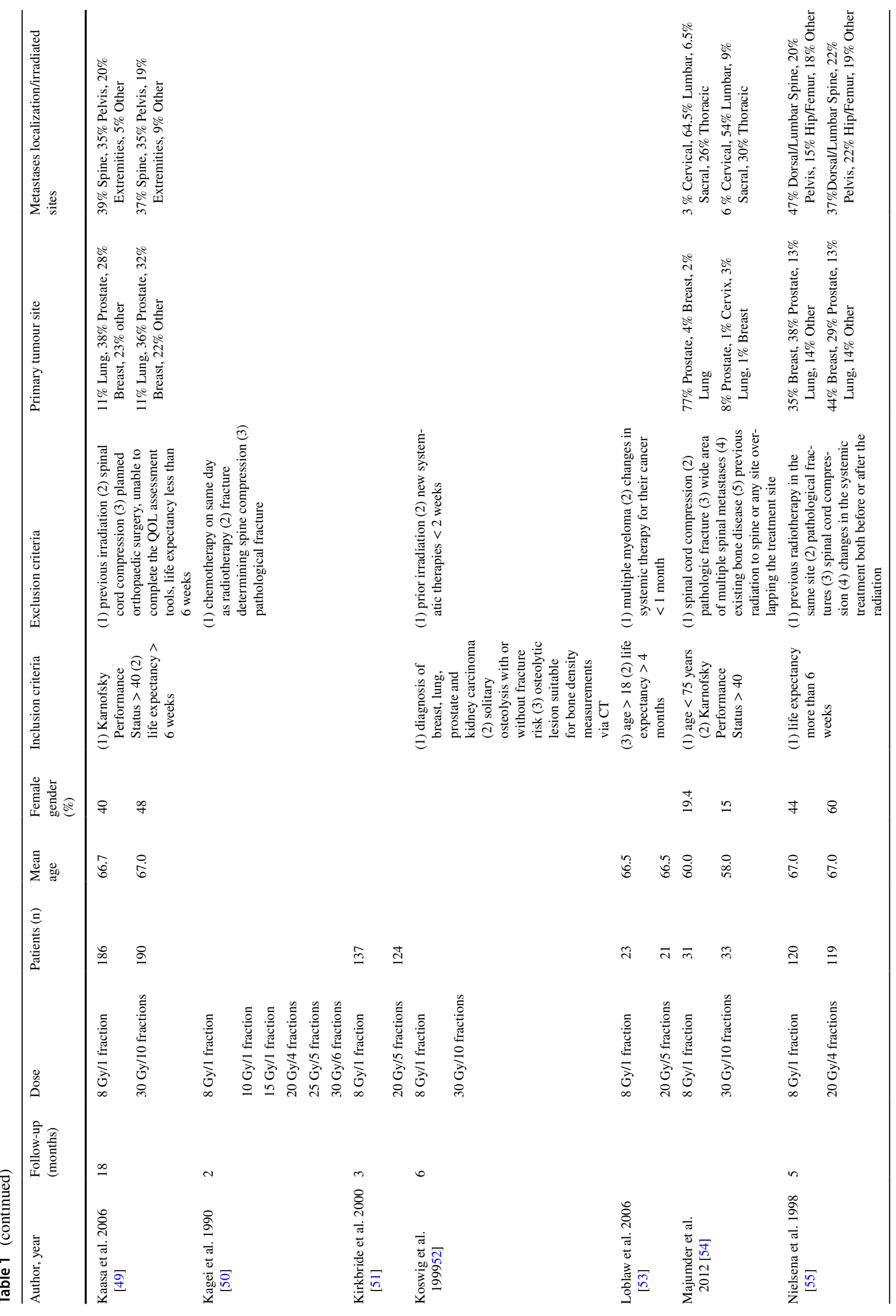




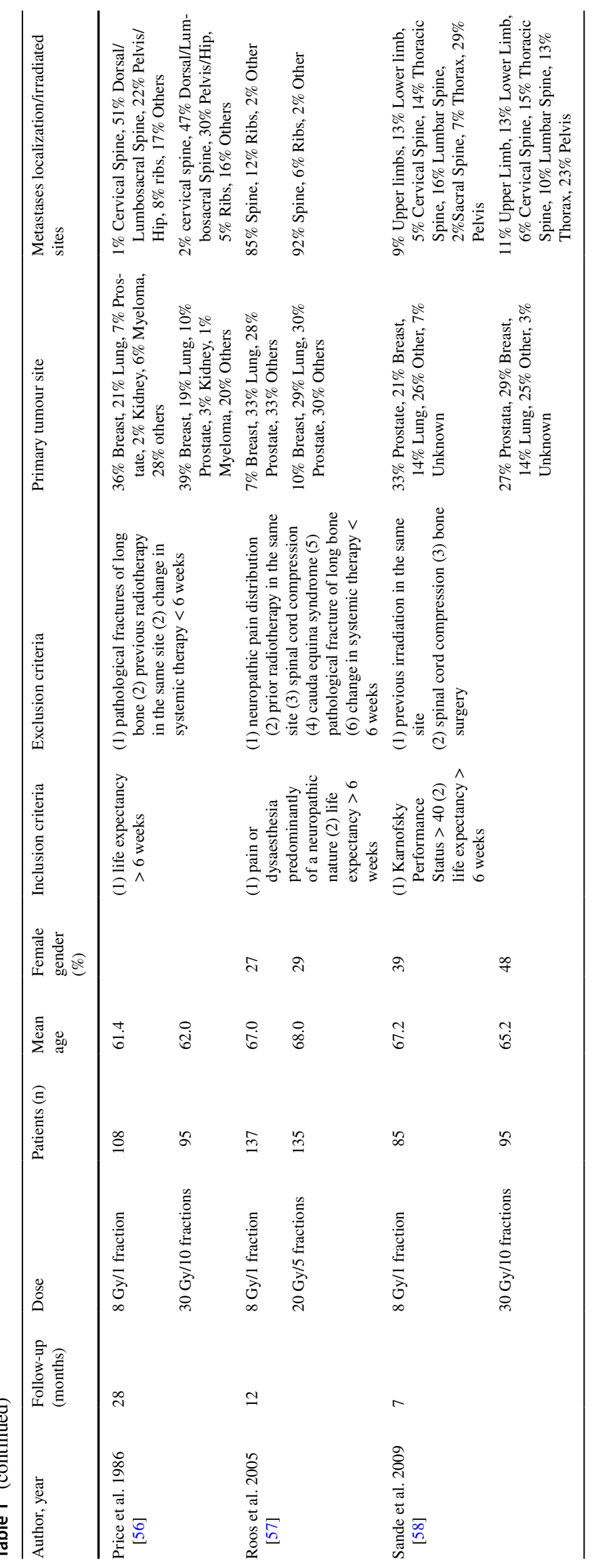




\section{Network comparisons}

The endpoint "no pain response" scored lower in the 8Gy group (LOR 3.39; SE 0.32; 95\% CI 2.77 to $4.00 ; 95 \%$ PrI 2.63 to 4.14$)$. The endpoint "complete pain remission" scored better in the 8Gy group (LOR -7.05; SE 0.29; 95\% CI -7.64 to -6.47 ; $95 \%$ PrI -8.14 to -5.97 ). The $8 \mathrm{~Gy}$ group demonstrated a better pain response to the therapy (LOR -5.88; SE $0.41 ; 95 \%$ CI -6.69 to -5.07 ; $95 \%$ PrI -8.49 to -3.26 ). The equation for global linearity via the Wald test detected no statically significant inconsistency (P $>0.5$ ). Results of the network comparisons concerning pain control are shown in Fig. 2.

The 8Gy group showed a lower rate of pathological fractures compared to the other groups (LOR 1.16; SE 0.65; 95\% CI -0.11 to 2.43 ; $95 \%$ PrI -1.85 to 4.18 ). In the $8 \mathrm{~Gy}$ group there was a significant lower rate of spinal cord compression compared to the other groups (LOR 1.31; SE 1.25; $95 \% \mathrm{CI}-1.14$ to $3.76 ; 95 \% \mathrm{PrI}-4.02$ to 6.64$)$. In terms of reduced re-irradiation, the the $8 \mathrm{~Gy}$ group detected reduced rate compared to the other cohorts (LOR 2.97; SE 0.58; 95\% CI 1.83 to $4.11 ; 95 \%$ PrI 0.21 to 5.73 ). The equation for global linearity via the Wald test detected no statically significant inconsistency $(\mathrm{P}>0.5)$. Results of the network comparisons concerning complications are shown in Fig. 3.

\section{Discussion}

This Bayesian network meta-analysis showed that a single dose of $8 \mathrm{~Gy} /$ one fraction radiation therapy is superior to multiple doses (20Gy and 30Gy) in terms of palliative control of pain in patients with skeletal metastases. Further, the $8 \mathrm{~Gy} /$ one fraction protocol showed lower rate re-irradiation and complications, such as spinal cord compression and fractures. No differences in survivorship between the different dose patterns was detected.

The palliative 8Gy radiotherapy group performed better overall. Administration of pain medication was significantly lower in the 8Gy group compared to the 30Gy group. The network analysis reported a statistically significant lower risk of pathological fracture and spinal cord compression in the 8Gy group compared to the 20Gy and 30Gy groups. Partial and overall pain recurrence were remarkably lower in the 8Gy group compared to both 20Gy and 30Gy groups. Furthermore, the $8 \mathrm{~Gy}$ group reported the lowest rate of nonresponse among patients. Concerning the endpoint of reirradiation, no statistical significance was detected between the regimens studied in the present report. Of note, one single fractionation of radiation offers greater patient and caregiver convenience.

The seed-and-soil theory hypothesize that, given several cytokines and growth factors, bone tissue (the soil) can 


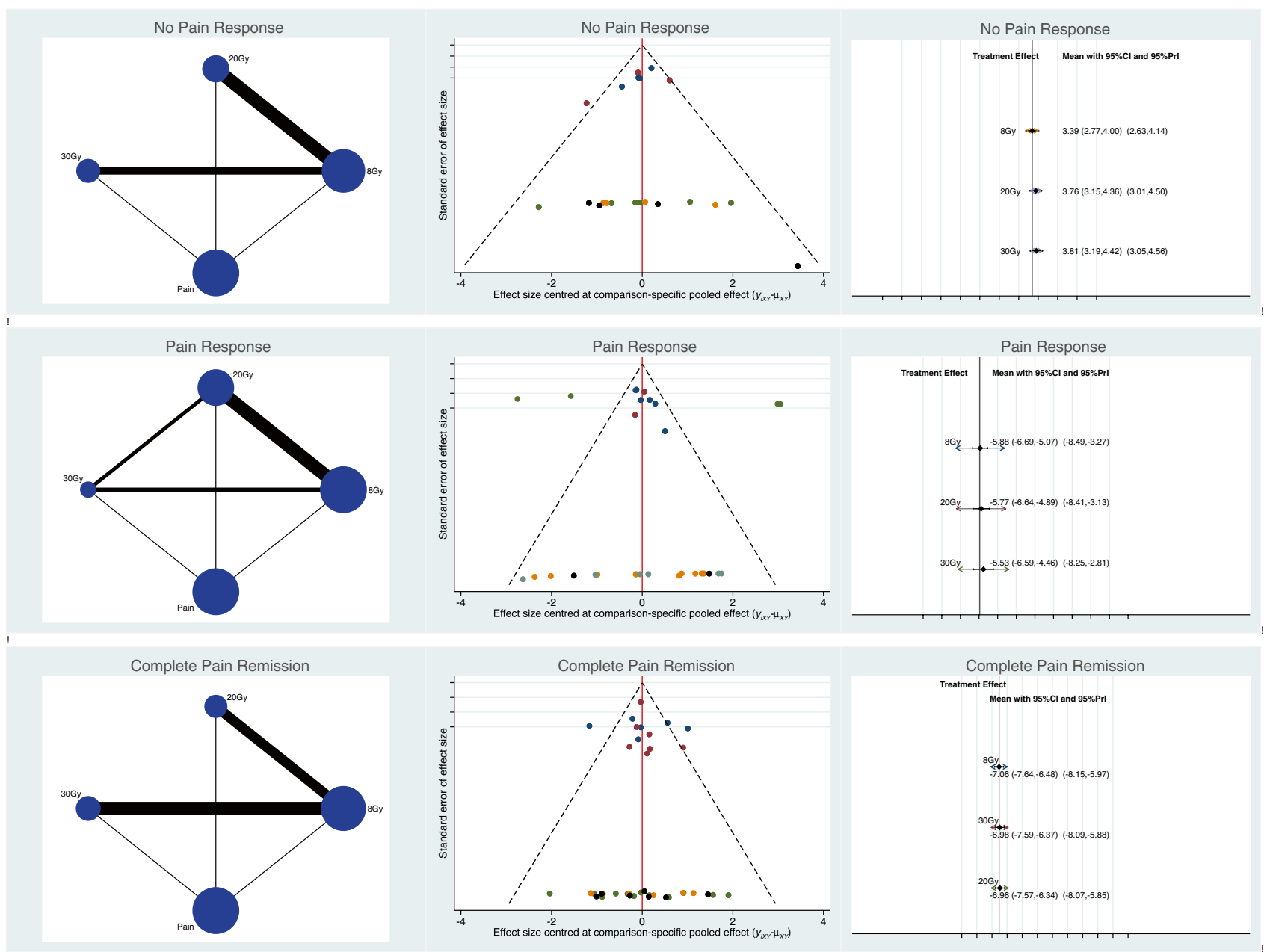

Fig. 2 Results of the network comparisons concerning pain control

provide an optimal field for the metastases (the seed) [19]. The process that leads to metastatic growth is regulated by a signalling pathway between the microenvironment and tumoral cells [20,21]. This signalling induces growth of the tumour by interacting with the bone homeostasis. The first studies on tumour genesis demonstrated a "vicious cycle" between bone and tumour cells [21]. Tumour cells secrete cytokines, such as parathyroid hormone related protein (PTHrP), stimulating the release of RANKL from osteoblasts, promoting osteoclast bone resorption [11, 22]. Bone resorption then releases growth factors, in turn promoting tumour growth, and the cycle continues. Modern anti-tumoral therapies are based on this rationale to directly inhibit osteoclasts [23]. However, some anti-tumour therapies such as hormone deprivation (anti-androgen or antioestrogen) or corticosteroids exert a negative impact on bone quality, resulting in osteoporosis [24]. Bisphosphonates, such as zoledronate, bind hydroxyapatite and interact with osteoclasts, promoting apoptosis, thus inhibiting bone resorption [25]. Bisphosphonates delay the advance of existing bone metastasis and reduce the risk of developing new bony lesions in patients with breast cancer and multiple myeloma [26, 27]. Bisphosphonates also reduce skeletal complications in hormone-refractory prostate cancer [28], non-small cell lung cancer, and other urologic malignancies $[29,30]$. Their use is recommended in patients affected by breast cancer with signs of bone metastasis [31]. Denosumab is a monoclonal antibody that inhibits RANKL activity, a ligand in the signalling pathway that regulates osteoclast differentiation and activation. Thus, there is widespread interest in it for bone metastasis treatment, particularly when zoledronate is no longer effective [32]. Furthermore, Denosumab does not accumulate in bone, allowing quick reversal after its suspension [32]. However, the considerably increased risk of jaw osteonecrosis represents a major complication of bisphosphonates [33]. External beam radiotherapy (EBRT) is a common alternative treatment options for pain in uncomplicated bone metastases [16]. Chow et al. [13] reported partial pain relief in $50 \%$ to $80 \%$ of patients with bone metastasis receiving EBRT. Furthermore, complete relief from 


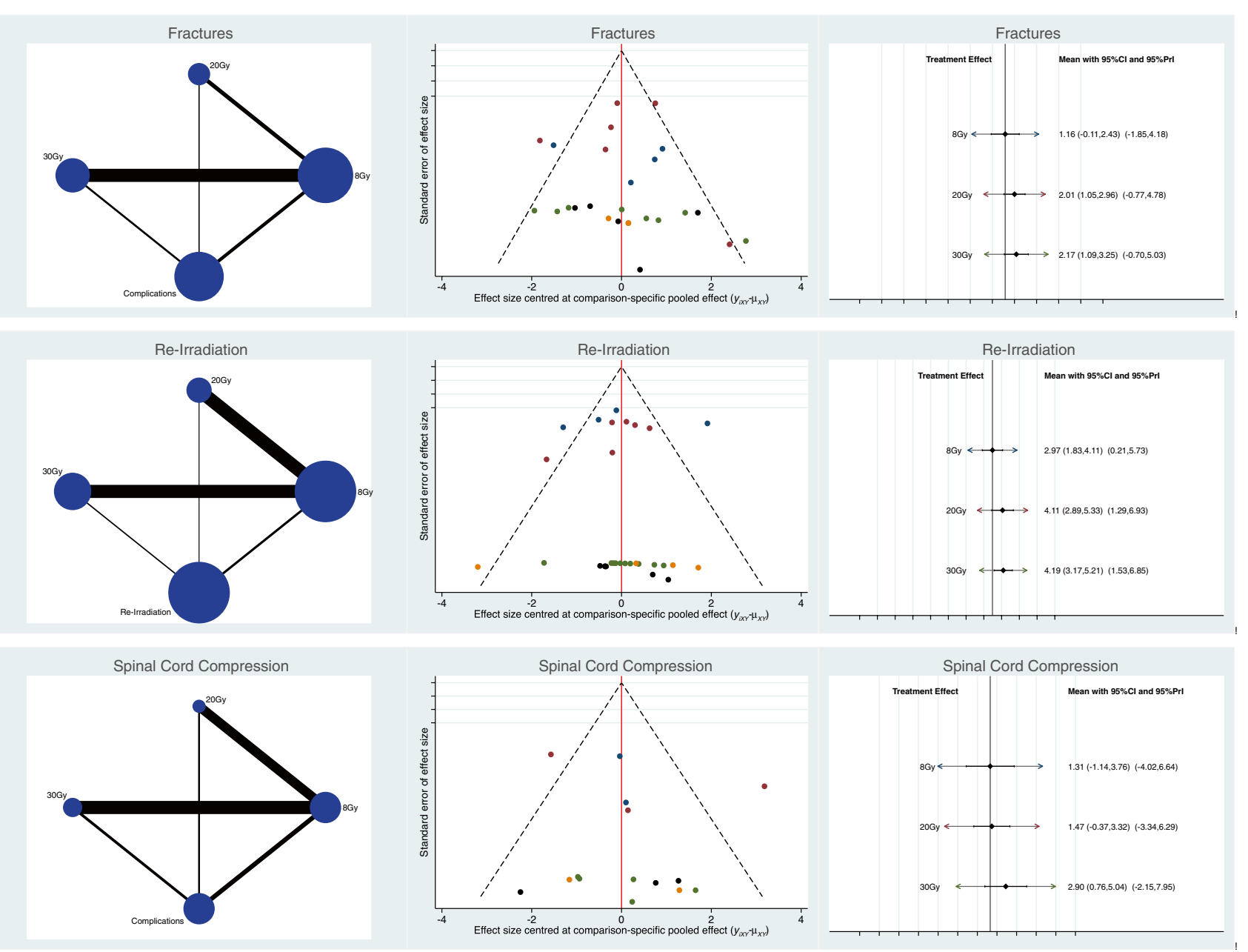

Fig. 3 Results of the network comparisons concerning complications.

metastatic bone pain was reported by almost $30 \%$ of patients [13]. Interestingly, the cause of pain in bone metastases is still unknown [34]. Radiation destroys tumour cells, promoting bone reparation, but the rapid pain relief poses a question on the true source of bone pain. Hoskin et al. [35] found a possible explanation of the reported pain relief after radiotherapy, hypothesising that the source of pain is intrinsic to the bone (osteoclasts) rather than the tumour. This partially explains the pain relief observed even with bisphosphonate treatment, as they directly act on the osteoclasts.

Regarding surgical intervention, an impending or frank pathological fracture from bone metastases is a classical indication for internal fixation. Surgery is also indicated when metastases cause spinal cord involvement or peripheral nerve compression. Two retrospective cohort studies evaluated the outcome of prophylactic surgical fixation of impending fractures [36, 37]. Fixation of impending fractures leads to a reduction of total blood loss, shorter hospitalization, improved function, and longer survival compared to surgical fixation of pathological fractures [36, 37]. The
Mirels score evaluates the potential necessity for prophylactic surgery [38]. Another way to evaluate the potential need for prophylactic surgery is the assessment of bone with CT scan [39]. This technique compares the structural rigidity of the bone matrix of the contralateral side and has shown superior sensitivity and specificity compared to Mirels criteria [39]. Surgical outcomes and survival, however, depend strictly on the preoperative health of a patient [40]. The Goldman classification is useful to evaluate patient pre-operative health status [41]. This score assesses the surgical risk based on cardiac, respiratory, and other secondary factors. Analysing death prognostic factors, Nathan et al. [42] found that primary diagnosis, use of systemic therapy, Eastern Cooperative Oncology Group (ECOG) performance status, number of bone metastases, presence of visceral metastases, and serum haemoglobin, albumin, and lymphocyte counts were significant in predicting survival.

Major points of strength of this Bayesian network metaanalysis are the comprehensive nature of the literature search and the strict eligibility criteria for study inclusion. Several 
different palliative fractionation schedules and doses (e.g. $12 \mathrm{~Gy}, 15 \mathrm{~Gy}, 16 \mathrm{~Gy}$ in one fraction, $22.5 \mathrm{~Gy}$ in 5 fractions, 24Gy in 6 fractions, 40Gy in 20 fractions, and many other) have been described [43]. Lack of data or low level of evidence, however, did not allow inclusion of some studies in the present meta-analysis. Thereby, only the most commonly used dose patterns were compared. The small number of RCTs included in this study represents the most important limitation. Furthermore, this reflects the lack of evidence and consensus on this topic. Further high-quality studies are required to improve our current understanding in this field. Other important limitations are the lack of data and the heterogeneous eligibility criteria among the studies included. This increases publication bias, which negatively influences our recommendation. Given the lack of quantitative data, it was not possible to analyse the different anatomical districs (spine, lower and upper limb) separately. Given these limitations, data from this study must be interpreted with caution.

\section{Conclusion}

Palliative $8 \mathrm{~Gy} /$ single fraction radiotherapy for skeletal metastases showed superior results compared to the other regimens. Consumption of pain medication was notably lower in the $8 \mathrm{~Gy}$ group compared to the $30 \mathrm{~Gy}$ group. The $8 \mathrm{~Gy} /$ single fraction demonstrated superiority to the other multiple dose patterns (20Gy and 30Gy) in controlling pain. Pathological fractures and spinal cord compressions occurred significantly less often in the $8 \mathrm{~Gy}$ group compared to $20 \mathrm{~Gy}$ and $30 \mathrm{~Gy}$ groups, along with a reduce rate of reirradiation. Furthermore, the $8 \mathrm{~Gy}$ group reported the lowest rate of non-response among patients. No differences in survivorship among the dose patterns was detected.

Funding Open Access funding enabled and organized by Projekt DEAL. No external source of funding was used.

\section{Compliance with ethical standards}

Conflict of interest The authors declare that they have no conflict of interest.

Ethical approval This article does not contain any studies with human participants or animals performed by any of the authors.

Informed consent For this type of study informed consent is not required.

Open Access This article is licensed under a Creative Commons Attribution 4.0 International License, which permits use, sharing, adaptation, distribution and reproduction in any medium or format, as long as you give appropriate credit to the original author(s) and the source, provide a link to the Creative Commons licence, and indicate if changes were made. The images or other third party material in this article are included in the article's Creative Commons licence, unless indicated otherwise in a credit line to the material. If material is not included in the article's Creative Commons licence and your intended use is not permitted by statutory regulation or exceeds the permitted use, you will need to obtain permission directly from the copyright holder. To view a copy of this licence, visit http://creativecommons.org/licenses/by/4.0/.

\section{References}

1. Migliorini F, Maffulli N, Trivellas A, Eschweiler J, Tingart M, Driessen A (2020) Bone metastases: a comprehensive review of the literature. Mol Biol Rep. https://doi.org/10.1007/s11033-02005684-0

2. Berenson JR, Rosen LS, Howell A, Porter L, Coleman RE, Morley W, Dreicer R, Kuross SA, Lipton A, Seaman JJ (2001) Zoledronic acid reduces skeletal-related events in patients with osteolytic metastases. Cancer 91(7):1191-1200. https://doi. org/10.1002/1097-0142(20010401)91:7\%3c1191::aid-cncr 1 $119 \% 3$ e3.0.co;2-0

3. Coleman RE (2001) Metastatic bone disease: clinical features, pathophysiology and treatment strategies. Cancer Treat Rev 27(3):165-176. https://doi.org/10.1053/ctrv.2000.0210

4. Selvaggi G, Scagliotti GV (2005) Management of bone metastases in cancer: a review. Crit Rev Oncol Hematol 56(3):365-378. https ://doi.org/10.1016/j.critrevonc.2005.03.011

5. Macedo F, Ladeira K, Pinho F, Saraiva N, Bonito N, Pinto L, Goncalves F (2017) Bone Metastases: An Overview. Oncol Rev 11(1):321. https://doi.org/10.4081/oncol.2017.321

6. Coleman RE (1997) Skeletal complications of malignancy. Cancer 80(8 Suppl):1588-1594. https://doi.org/10.1002/(sici)10970142(19971015)80:8+\%3c1588::aid-cncr9\%3e3.3.co;2-z

7. Coleman RE (2006) Clinical features of metastatic bone disease and risk of skeletal morbidity. Clin Cancer Res 12(20 Pt 2):6243s-6249s. https://doi.org/10.1158/1078-0432.CCR-06-0931

8. Healey JH, Turnbull AD, Miedema B, Lane JM (1986) Acrometastases. A study of twenty-nine patients with osseous involvement of the hands and feet. J Bone Joint Surg Am 68(5):743-746

9. Li S, Peng Y, Weinhandl ED, Blaes AH, Cetin K, Chia VM, Stryker S, Pinzone JJ, Acquavella JF, Arneson TJ (2012) Estimated number of prevalent cases of metastatic bone disease in the US adult population. Clin Epidemiol 4:87-93. https://doi. org/10.2147/CLEP.S28339

10. Jemal A, Bray F, Center MM, Ferlay J, Ward E, Forman D (2011) Global cancer statistics. CA Cancer J Clin 61(2):69-90. https:// doi.org/10.3322/caac. 20107

11. Yoneda T, Sasaki A, Mundy GR (1994) Osteolytic bone metastasis in breast cancer. Breast Cancer Res Treat 32(1):73-84

12. Spencer K, Parrish R, Barton R, Henry A (2018) Palliative radiotherapy. BMJ 360:k821. https://doi.org/10.1136/bmj.k821

13. Chow E, Harris K, Fan G, Tsao M, Sze WM (2007) Palliative radiotherapy trials for bone metastases: a systematic review. J Clin Oncol 25(11):1423-1436. https://doi.org/10.1200/ JCO.2006.09.5281

14. Fairchild A, Barnes E, Ghosh S, Ben-Josef E, Roos D, Hartsell W, Holt T, Wu J, Janjan N, Chow E (2009) International patterns of practice in palliative radiotherapy for painful bone metastases: evidence-based practice? Int J Radiat Oncol Biol Phys 75(5):1501-1510. https://doi.org/10.1016/j.ijrobp.2008.12.084

15. De Felice F, Piccioli A, Musio D, Tombolini V (2017) The role of radiation therapy in bone metastases management. Oncotarget 8(15):25691-25699. https://doi.org/10.18632/oncotarget.14823 
16. Lutz S, Berk L, Chang E, Chow E, Hahn C, Hoskin P, Howell D, Konski A, Kachnic L, Lo S, Sahgal A, Silverman L, von Gunten C, Mendel E, Vassil A, Bruner DW, Hartsell W, American Society for Radiation O (2011) Palliative radiotherapy for bone metastases: an ASTRO evidence-based guideline. Int J Radiat Oncol Biol Phys 79(4):965-976. https://doi.org/10.1016/j.ijrobp.2010.11.026

17. Hutton B, Salanti G, Caldwell DM, Chaimani A, Schmid CH, Cameron C, Ioannidis JP, Straus S, Thorlund K, Jansen JP, Mulrow C, Catala-Lopez F, Gotzsche PC, Dickersin K, Boutron I, Altman DG, Moher D (2015) The PRISMA extension statement for reporting of systematic reviews incorporating network meta-analyses of health care interventions: checklist and explanations. Ann Intern Med 162(11):777-784. https://doi.org/10.7326/M14-2385

18. Howick J CI GP, Greenhalgh T, Heneghan C, Liberati A, Moschetti I, Phillips B, Thornton H, Goddard O, Hodgkinson M The 2011 Oxford Levels of Evidence. Oxford Centre for EvidenceBased Medicine 2011

19. Papotti M, Kalebic T, Volante M, Chiusa L, Bacillo E, Cappia S, Lausi P, Novello S, Borasio P, Scagliotti GV (2006) Bone sialoprotein is predictive of bone metastases in resectable non-smallcell lung cancer: a retrospective case-control study. J Clin Oncol 24(30):4818-4824. https://doi.org/10.1200/JCO.2006.06.1952

20. Guise TA, Mundy GR (1998) Cancer and bone. Endocr Rev 19(1):18-54. https://doi.org/10.1210/edrv.19.1.0323

21. Johnson RW, Nguyen MP, Padalecki SS, Grubbs BG, Merkel AR, Oyajobi BO, Matrisian LM, Mundy GR, Sterling JA (2011) TGF-beta promotion of Gli2-induced expression of parathyroid hormone-related protein, an important osteolytic factor in bone metastasis, is independent of canonical Hedgehog signaling. Cancer Res 71(3):822-831. https://doi.org/10.1158/0008-5472. CAN-10-2993

22. Lewis CE, Pollard JW (2006) Distinct role of macrophages in different tumor microenvironments. Cancer Res 66(2):605-612. https://doi.org/10.1158/0008-5472.CAN-05-4005

23. Mundy GR (2002) Metastasis to bone: causes, consequences and therapeutic opportunities. Nat Rev Cancer 2(8):584-593. https:// doi.org/10.1038/nrc867

24. Coleman R, Body JJ, Aapro M, Hadji P, Herrstedt J, Gruoup ECW (2014) Bone health in cancer patients: ESMO Clinical Practice Guidelines. Ann Oncol 25(3):iii124-137. https://doi.org/10.1093/ annonc/mdu 103

25. Russell RG (2011) Bisphosphonates: the first 40 years. Bone 49(1):2-19. https://doi.org/10.1016/j.bone.2011.04.022

26. McCloskey EV, MacLennan IC, Drayson MT, Chapman C, Dunn J, Kanis JA (1998) A randomized trial of the effect of clodronate on skeletal morbidity in multiple myeloma. MRC Working Party on Leukaemia in Adults. Br J Haematol 100(2):317-325. https:// doi.org/10.1046/j.1365-2141.1998.00567.x

27. Powles T, Paterson S, Kanis JA, McCloskey E, Ashley S, Tidy A, Rosenqvist K, Smith I, Ottestad L, Legault S, Pajunen M, Nevantaus A, Mannisto E, Suovuori A, Atula S, Nevalainen J, Pylkkanen L (2002) Randomized, placebo-controlled trial of clodronate in patients with primary operable breast cancer. J Clin Oncol 20(15):3219-3224. https://doi.org/10.1200/JCO.2002.11.080

28. Saad F, Gleason DM, Murray R, Tchekmedyian S, Venner P, Lacombe L, Chin JL, Vinholes JJ, Goas JA, Chen B, Zoledronic Acid Prostate Cancer Study G (2002) A randomized, placebo-controlled trial of zoledronic acid in patients with hormone-refractory metastatic prostate carcinoma. J Natl Cancer Inst 94(19):14581468. https://doi.org/10.1093/jnci/94.19.1458

29. Rosen LS, Gordon D, Tchekmedyian S, Yanagihara R, Hirsh V, Krzakowski M, Pawlicki M, de Souza P, Zheng M, Urbanowitz G, Reitsma D, Seaman JJ (2003) Zoledronic acid versus placebo in the treatment of skeletal metastases in patients with lung cancer and other solid tumors: a phase III, double-blind, randomized trial-the Zoledronic Acid Lung Cancer and Other Solid
Tumors Study Group. J Clin Oncol 21(16):3150-3157. https://doi. org/10.1200/JCO.2003.04.105

30. Rosen LS, Gordon D, Kaminski M, Howell A, Belch A, Mackey J, Apffelstaedt J, Hussein MA, Coleman RE, Reitsma DJ, Chen BL, Seaman JJ (2003) Long-term efficacy and safety of zoledronic acid compared with pamidronate disodium in the treatment of skeletal complications in patients with advanced multiple myeloma or breast carcinoma: a randomized, double-blind, multicenter, comparative trial. Cancer 98(8):1735-1744. https://doi. org/10.1002/cncr.11701

31. Hillner BE, Ingle JN, Chlebowski RT, Gralow J, Yee GC, Janjan NA, Cauley JA, Blumenstein BA, Albain KS, Lipton A, Brown S (2003) American Society of Clinical Oncology 2003 update on the role of bisphosphonates and bone health issues in women with breast cancer. J Clin Oncol 21(21):4042-4057. https://doi. org/10.1200/JCO.2003.08.017

32. Yee AJ, Raje NS (2012) Denosumab, a RANK ligand inhibitor, for the management of bone loss in cancer patients. Clin Intery Aging 7:331-338. https://doi.org/10.2147/CIA.S14566

33. Migliorati CA, Epstein JB, Abt E, Berenson JR (2011) Osteonecrosis of the jaw and bisphosphonates in cancer: a narrative review. Nat Rev Endocrinol 7(1):34-42. https://doi.org/10.1038/ nrendo.2010.195

34. Maisano R, Pergolizzi S, Cascinu S (2001) Novel therapeutic approaches to cancer patients with bone metastasis. Crit Rev Oncol Hematol 40(3):239-250

35. Hoskin PJ, Stratford MR, Folkes LK, Regan J, Yarnold JR (2000) Effect of local radiotherapy for bone pain on urinary markers of osteoclast activity. Lancet 355(9213):1428-1429. https://doi. org/10.1016/s0140-6736(00)02144-9

36. Ward WG, Holsenbeck S, Dorey FJ, Spang J, Howe D (2003) Metastatic disease of the femur: surgical treatment. Clin Orthop Relat Res 415:S230-244. https://doi.org/10.1097/01.blo.00000 93849.72468.82

37. Katzer A, Meenen NM, Grabbe F, Rueger JM (2002) Surgery of skeletal metastases. Arch Orthop Trauma Surg 122(5):251-258. https://doi.org/10.1007/s00402-001-0359-2

38. Mirels H (1989) Metastatic disease in long bones. A proposed scoring system for diagnosing impending pathologic fractures. Clin Orthop Relat Res 249:256-264

39. Snyder BD, Hauser-Kara DA, Hipp JA, Zurakowski D, Hecht AC, Gebhardt MC (2006) Predicting fracture through benign skeletal lesions with quantitative computed tomography. J Bone Joint Surg Am 88(1):55-70. https://doi.org/10.2106/JBJS.D.02600

40. Cheung FH (2014) The practicing orthopedic surgeon's guide to managing long bone metastases. Orthop Clin North Am 45(1):109-119. https://doi.org/10.1016/j.ocl.2013.09.003

41. Goldman L, Caldera DL, Nussbaum SR, Southwick FS, Krogstad D, Murray B, Burke DS, O'Malley TA, Goroll AH, Caplan CH, Nolan J, Carabello B, Slater EE (1977) Multifactorial index of cardiac risk in noncardiac surgical procedures. N Engl J Med 297(16):845-850. https://doi.org/10.1056/NEJM19771020297 1601

42. Nathan SS, Healey JH, Mellano D, Hoang B, Lewis I, Morris CD, Athanasian EA, Boland PJ (2005) Survival in patients operated on for pathologic fracture: implications for end-of-life orthopedic care. J Clin Oncol 23(25):6072-6082. https://doi.org/10.1200/ JCO.2005.08.104

43. Sze WM, Shelley M, Held I, Mason M (2004) Palliation of metastatic bone pain: single fraction versus multifraction radiotherapy - a systematic review of the randomised trials. Cochrane Database Syst Rev. https://doi.org/10.1002/14651858.CD004721

44. Amouzegar-Hashemi F, Behrouzi H, Kazemian A, Zarpak B, Haddad P (2008) Single versus multiple fractions of palliative radiotherapy for bone metastases: a randomized clinical trial in 
Iranian patients. Curr Oncol 15(3):151. https://doi.org/10.3747/ co.v15i3.203

45. 8 Gy single fraction radiotherapy for the treatment of metastatic skeletal pain: randomised comparison with a multifraction schedule over 12 months of patient follow-up. Bone Pain Trial Working Party (1999). Radiother Oncol 52(2):111-121

46. Foro Arnalot P, Fontanals AV, Galceran JC, Lynd F, Latiesas XS, de Dios NR, Castillejo AR, Bassols ML, Galan JL, Conejo IM, Lopez MA (2008) Randomized clinical trial with two palliative radiotherapy regimens in painful bone metastases: $30 \mathrm{~Gy}$ in 10 fractions compared with $8 \mathrm{~Gy}$ in single fraction. Radiother Oncol 89(2):150-155. https://doi.org/10.1016/j.radonc.2008.05.018

47. Gutierrez Bayard L, Salas Buzon Mdel C, Angulo Pain E, de Ingunza Baron L (2014) Radiation therapy for the management of painful bone metastases: Results from a randomized trial. Rep Pract Oncol Radiother 19(6):405-411. https://doi.org/10.1016/j. rpor.2014.04.009

48. Hartsell WF, Scott CB, Bruner DW, Scarantino CW, Ivker RA, Roach M 3rd, Suh JH, Demas WF, Movsas B, Petersen IA, Konski AA, Cleeland CS, Janjan NA, DeSilvio M (2005) Randomized trial of short- versus long-course radiotherapy for palliation of painful bone metastases. J Natl Cancer Inst 97(11):798-804. https ://doi.org/10.1093/jnci/dji139

49. Kaasa S, Brenne E, Lund JA, Fayers P, Falkmer U, Holmberg M, Lagerlund M, Bruland O (2006) Prospective randomised multicenter trial on single fraction radiotherapy ( $8 \mathrm{~Gy}$ x 1 ) versus multiple fractions ( $3 \mathrm{~Gy} \times 10$ ) in the treatment of painful bone metastases. Radiother Oncol 79(3):278-284. https://doi.org/10.1016/j. radonc.2006.05.006

50. Kagei K, Suzuki K, Shirato H, Nambu T, Yoshikawa H, Irie G (1990) A randomized trial of single and multifraction radiation therapy for bone metastasis: a preliminary report. Gan No Rinsho 36(15):2553-2558

51. Kirkbride PWP, Panzarella T, Aslanidis J, McKenzie M, Sun A (2000) A randomised trial comparing the efficacy of a single radiaton fraction with fractionated radiation therapy in the palliation of skeletal metastases. Int J Rad Onc Biol Phys 48:185-185. https://doi.org/10.1016/S0360-3016(00)80164-9

52. Koswig S, Budach V (1999) Remineralization and pain relief in bone metastases after after different radiotherapy fractions (10 times 3 Gy vs. 1 time 8 Gy). A prospective study. Strahlenther Onkol 175(10):500-508

53. Loblaw DA, Wu JS, Kirkbride P, Panzarella T, Smith K, Aslanidis J, Warde P (2007) Pain flare in patients with bone metastases after palliative radiotherapy-a nested randomized control trial. Support Care Cancer 15(4):451-455. https://doi.org/10.1007/s0052 0-006-0166-y

54. Majumder D, Chatterjee D, Bandyopadhyay A, Mallick SK, Sarkar SK, Majumdar A (2012) Single Fraction versus Multiple Fraction Radiotherapy for Palliation of Painful Vertebral Bone Metastases: A Prospective Study. Indian J Palliat Care 18(3):202206. https://doi.org/10.4103/0973-1075.105691

55. Nielsena OSBS, Sandbergc E, Gadebergd CG, Timothye AR (1998) Randomized trial of single dose versus fractionated palliative radiotherapy of bone metastases. Rad Onc 47(3):233-240. https://doi.org/10.1016/S0167-8140(98)00011-5

56. Price P, Hoskin PJ, Easton D, Austin D, Palmer SG, Yarnold JR (1986) Prospective randomised trial of single and multifraction radiotherapy schedules in the treatment of painful bony metastases. Radiother Oncol 6(4):247-255. https://doi.org/10.1016/s0167 $-8140(86) 80191-8$

57. Roos DE, Turner SL, O’Brien PC, Smith JG, Spry NA, Burmeister BH, Hoskin PJ, Ball DL, Trans-Tasman Radiation Oncology Group T (2005) Randomized trial of 8 Gy in 1 versus 20 Gy in 5 fractions of radiotherapy for neuropathic pain due to bone metastases (Trans-Tasman Radiation Oncology Group, TROG 9605). Radiother Oncol 75(1):54-63. https://doi.org/10.1016/j. radonc.2004.09.017

58. Sande TA, Ruenes R, Lund JA, Bruland OS, Hornslien K, Bremnes R, Kaasa S (2009) Long-term follow-up of cancer patients receiving radiotherapy for bone metastases: results from a randomised multicentre trial. Radiother Oncol 91(2):261-266. https://doi.org/10.1016/j.radonc.2009.02.014

Publisher's Note Springer Nature remains neutral with regard to jurisdictional claims in published maps and institutional affiliations. 